\title{
Um modelo de avaliação do realismo, da interatividade e da sensação de presença na realidade virtual: a difusão científica em vídeos 360 graus no YouTube
}

\author{
A model for evaluating realism, interactivity and the feeling of presence in virtual reality: scientific \\ diffusion in 360-degree videos on YouTube \\ Un modelo para evaluar el realismo, la interactividad y el sentimiento de presencia en la realidad \\ virtual: difusión científica en videos 360 grados en YouTube
}

Recebido: 16/12/2021 | Revisado: 23/12/2021 | Aceito: 04/02/2022 | Publicado: 05/02/2022

\author{
Thais May Carvalho \\ ORCID: https://orcid.org/0000-0001-7493-8884 \\ CEPID NeuroMat, Brasil \\ E-mail: thaismaycarvalho@outlook.com \\ João Alexandre Peschanski \\ ORCID: https://orcid.org/0000-0002-2352-1787 \\ Faculdade Cásper Líbero, Brasil \\ E-mail: japeschanski@casperlibero.edu.br
}

\begin{abstract}
Resumo
A realidade virtual (RV) é reconhecidamente uma tecnologia com grande capacidade imersiva, ou seja, ela faz o espectador sentir como se estivesse vivenciando aquela experiência em primeira-mão. Por meio da literatura foi possível observar que a imersão na RV está diretamente ligada à como são construídos o realismo, a interatividade e a sensação de presença. A partir das características específicas de cada um desses três elementos foi elaborada uma ficha de análise para verificar como vídeos em 360 graus trabalham esses quesitos. A fim de testar a ficha elaborada, em um segundo momento foi realizado um estudo de caso com vídeos de difusão científica feitos em $360^{\circ}$, que estão em português e disponíveis no YouTube. A escolha pela área da difusão científica se deu pelo fato de que, segundo a literatura, ela precisa encontrar formas novas e mais criativas de se aproximar do público, e a RV, justamente por seu caráter imersivo, mostra grande potencial nesse sentido. Na análise foi observado que não há uma uniformidade na maneira como o realismo, a interatividade e a sensação de presença são trabalhados nos vídeos selecionados.
\end{abstract}

Palavras-chave: Realidade virtual; Realismo; Interatividade; Sensação de presença; Difusão científica.

\begin{abstract}
Virtual reality (VR) is recognized as a technology with great immersive capacity, that is, it makes the viewer feel as if they are experiencing everything first-hand. Through the literature, it was possible to observe that immersion in VR is directly linked to how realism, interactivity and the feeling of presence are constructed. Based on the specific characteristics of each of these three elements, an analysis card was created to verify how 360-degree videos work with those items. To test this card, in a second moment, scientific diffusion videos made in $360^{\circ}$, which are in Portuguese and available on YouTube, were analyzed in the study case. The choice for scientific diffusion was due to the fact that, according to the literature, it needs to find new and more creative ways of approaching the public, and VR, because of its immersive nature, shows great potential in this regard. In the analysis it was observed that there is no uniformity in the way in which realism, interactivity and the sense of presence are worked in the selected videos.
\end{abstract}

Keywords: Virtual reality; Realism; Interactivity; Feeling of presence; Scientific diffusion.

\section{Resumen}

La realidad virtual (RV) es reconocida como una tecnología con gran capacidad inmersiva, es decir, hace sentir al espectador como si estuviera viviendo esa experiencia de primera mano. A través de la literatura se pudo observar que la inmersión en la RV está directamente ligada a cómo se construye el realismo, la interactividad y la sensación de presencia. Con base en las características específicas de cada uno de estos tres elementos, se creó una ficha de análisis para verificar cómo los videos de 360 grados abordan estos temas. Para probar el formulario elaborado, en un segundo momento se realizó un estudio de caso con videos de difusión científica realizados en $360^{\circ}$, que se encuentran en portugués y disponibles en YouTube. La elección por el área de difusión científica se debió a que, según la literatura, necesita encontrar formas nuevas y más creativas de acercarse al público, y la RV, precisamente por su naturaleza inmersiva, muestra un gran potencial en este respecto. En el análisis se observó que no existe uniformidad en la forma en que se trabaja el realismo, la interactividad y el sentido de presencia en los videos seleccionados.

Palabras clave: Realidad virtual; Realismo; Interactividad; Sentimiento de presencia; Difusión científica. 


\section{Introdução}

Nas últimas três décadas, a realidade virtual (RV) ganhou cada vez mais espaço no campo da comunicação (Hardee, 2016; Pérez Seijo, 2017). Esse tipo de mídia permite que o espectador se conecte de uma forma mais próxima com o conteúdo apresentado (Comber et al., 2018; Hardee, 2016; Kool, 2016; Owen et al., 2015) por sua forte característica imersiva, que vai além do que outros meios proporcionam (Laws, 2020; Slater, 2009).

Quais são os elementos necessários para a imersão do espectador no conteúdo em realidade virtual? Esta é a pergunta central deste artigo e, para respondê-la, faz-se neste artigo uma seleção de critérios para analisar a imersão. Com base em uma revisão de literatura sistemática, foi feita uma ficha de avaliação, que posteriormente foi testada com vídeos produzidos em tecnologia 360 graus. Os vídeos selecionados são de divulgação científica, uma área em que a imersão é especialmente relevante para aproximar ciência e público (Burkett, 1990; Torres, 2017) e, por isso, na qual a RV pode ter boa penetração (Foletto e Souza, 2019).

\subsection{Realidade virtual}

A realidade virtual pode ser definida como uma mídia imersiva, na qual os ambientes são construídos de forma realista, seja a partir de um vídeo filmado em $360^{\circ}$ ou feito com simulações de computadores em três dimensões (Owen et al., 2015). Nela os usuários se sentem presentes no mundo virtual e isso permite com que o público possa interagir diretamente com o conteúdo (Gorini et al., 2010; Owen et al., 2015; Steuer, 1992).

Entende-se por imersão o escape da realidade vivida e a entrada temporária em um outro ambiente, virtual e experimentado como um personagem de história (Cordeiro e Costa, 2016). De acordo com Domínguez (p. 2, 2017), a imersão é necessária "para transmitir ao leitor a sensação de estar dentro de uma outra realidade".

De acordo com Slater (p. 3549, 2009), a RV tem o potencial de "ir muito além de tudo o que já foi experimentado antes em termos de transcender os limites da realidade física, por meio da transformação do seu senso de lugar e por meio de alterações não invasivas do sentido do nosso próprio corpo". Para Longhi e Pereira (p. 9, 2016), essa tecnologia gera o "esmaecimento das fronteiras entre o mundo real e o mundo representado", o que permite ao usuário um acesso inédito e muito mais próximo ao conteúdo apresentado (Kool, 2016).

$\mathrm{O}$ emprego da RV é um fenômeno recente no meio jornalístico. Os primeiros estudos e experimentações na área aconteceram a partir dos anos 1980 (Doyle et., 2016; Hardee, 2016; Pérez Seijo, 2017), mas seu uso mais difundido na comunicação só passou a acontecer no começo da década de 2010, quando ocorreu o investimento de grandes empresas nessa tecnologia, tornandoa mais barata e acessível aos veículos de comunicação e ao público em geral (Doyle et al., 2016; Jones, 2017; Longhi e Pereira, 2016; Rupp et al., 2019). Os principais atrativos das narrativas em RV para o jornalismo são: a capacidade de fazer o espectador se sentir presente na cena; o realismo do cenário retratado; e a interatividade que essa experiência proporciona (Owen et al., 2015; Sundar et al., 2017).

A expectativa do uso da RV na comunicação é que ela permita uma experiência transformadora para quem a experimenta, no sentido de sentir-se engajado, como um participante ativo da história que está sendo retratada (Domínguez, 2017; Kool, 2016; Laws, 2020). O usuário de RV não só vê, lê ou ouve relatos sobre o que aconteceu, mas é inserido no meio daquele evento, o que lhe permite a sensação de experimentá-lo de forma mais próxima, em primeira mão (Peña et al., 2010), ou seja, há uma imersão no conteúdo. Por isso, segundo Elmezeny et al. (2018, p. 10), "se utilizado no contexto correto, o formato de $360^{\circ}$ pode ajudar a engajar e conectar espectadores a assuntos sérios, da sociedade civil à política e problemas ambientais". 
Quando se trata de conteúdos jornalísticos, a imersão está relacionada a três características de acordo com a literatura, abordadas a seguir: o realismo, a interatividade e a sensação de presença.

\section{Realismo}

Um desafio do jornalismo em RV é fazer com que os elementos do mundo virtual sejam críveis e fidedignos à realidade, a ponto de fazer o espectador pensar que está inserido naquele cenário (Hardee, 2016). Logo, para que uma experiência seja realista em RV (especialmente quando se fala em animação), ela deve apresentar os seguintes elementos:

- Verossimilhança: quanto mais próximo do mundo real o conteúdo for, maior a sensação de realismo. Então, o que é experimentado no ambiente virtual precisa ter um correspondente similar no mundo real e ser familiar ao espectador (Christou e Parker, 1995; Domínguez, 2017; Nikolic, 2007; Van Gisbergen et al., 2019). Para isso são importantes o jogo de luz e sombra, a textura e solidez das superfícies, a perspectiva e profundidade do ambiente, a adequação das proporções, a presença de vários tons de cor, o campo de visão ser panorâmico (Christou e Parker, 1995; Nikolic, 2007; Slater et al., 2009; Slater e Wilbur, 1997), e o som surround (Domínguez, 2017; Fox et al., 2009; Slater e Wilbur, 1997). Outro aspecto importante para a verossimilhança é a boa qualidade das resoluções da imagem e do som (Slater e Wilbur, 1997; Steuer, 1992).

- Riqueza de detalhes e informações: quanto mais detalhes e informações estão presentes, mais realista é o ambiente virtual (Christou e Parker, 1995; Slater e Wilbur, 1997). Uma pesquisa realizada por Van Gisbergen et al. (2019) mostra que quanto mais detalhes são adicionados a um cenário, mais o público tem a sensação de que aquele ambiente é real.

- Naturalidade: Christou e Parker (1995), Nikolic (2007) e Slater et al. (2009) afirmam que mesmo que um objeto, uma cena ou uma pessoa sejam verossímeis, eles também precisam se comportar de forma natural para que o conjunto como um todo pareça real e proporcione uma experiência realista.

- Multiplicidade de estímulos sensoriais e motores: quanto mais o corpo do espectador está envolvido no processo narrativo, mais real tudo aquilo parece. Logo, uma experiência mais realista envolve audição, visão, olfato, tato e o movimento das várias partes do corpo (Christou e Parker, 1995; Comber et al., 2018; Kool, 2016; Steuer, 1992).

Vale ressaltar que alguns pesquisadores apontam para o fato de que o mundo virtual não precisa ser completamente igual ao mundo real para ser considerado realista. Desde que a narrativa tenha uma continuidade, uma lógica interna, que possa ser identificada pelo espectador, e que aconteça uma conexão com o conteúdo, haverá realismo mesmo num ambiente de fantasia (Domínguez, 2017; Van Gisbergen et al., 2019; Witmer e Singer, 1998).

Também existem elementos que afetam negativamente o realismo. No caso das animações, se uma das representações fica com uma qualidade um pouco mais baixa, se ela não parece tão real como o restante do cenário, a sensação de realismo é prejudicada (Van Gisbergen et al., 2019). Quanto mais visível a mídia ficar, ou seja, quanto mais os bits, os códigos e a tela ficarem aparentes, menos realista aquele ambiente parece - esse é um dos motivos pelos quais o headset é melhor para consumir esse tipo de conteúdo, pois a tela some (Ryan, 1999). No caso dos vídeos filmados com câmeras de $360^{\circ}$, quando elementos artificiais são inseridos - como textos, gráficos, desenhos ou movimentos colocados na pós-produção -, mesmo que eles ajudem com o desenvolver da história ou facilitem a visualização, a percepção de realismo do espectador acaba diminuindo, pois há uma quebra na naturalidade (Kool, 2016; Lin et al., 2017).

\section{Interatividade}

A interatividade é fundamental para a experiência em RV, sendo o principal aspecto que a diferencia de outras formas de comunicação (Domínguez, 2017), afinal "a RV e o vídeo $360^{\circ}$ dão aos usuários o poder não apenas de responder ao conteúdo 
jornalístico, como foi o caso com formas anteriores de 'conteúdo gerado pelo usuário', mas também de moldar ativamente a história e, portanto, sua própria experiência” (Mabrook e Singer, p. 5, 2019). Shin e Biocca (2017) corroboram com essa ideia quando dizem que os avanços tecnológicos mudaram o papel do público, que passou de consumidor passivo do conteúdo fornecido pela mídia para o de criador da própria imersão, já que a participação lhe permite construir sua experiência. Maschio (2017) classifica a RV como uma forma de storyliving, e não somente como storytelling. Enquanto no storytelling o consumo é passivo e há a reencenação de algo que aconteceu anteriormente com uma pessoa, na realidade virtual (storyliving) a experiência é imersiva e permite que as coisas aconteçam com o espectador no aqui e agora.

Para se ter um conteúdo interativo, é preciso levar em consideração os seguintes aspectos: o envolvimento dos diversos sentidos (como audição, visão e tato); a velocidade (o quão rápido o mundo virtual responde à ação no mundo real); a variedade (quantas ações o sistema comporta); e a correspondência (quão verossímil é o movimento no ambiente virtual ao que seria na realidade física) (Reis e Coelho, 2018; Ryan, 1999; Slater e Wilbur, 1997; Steuer, 1992).

O vídeo em $360^{\circ}$ (seja ele filmado com uma câmera esférica ou feito com animação 3D) tem a forma mais baixa de interatividade no espectro da RV. Enquanto o usuário é colocado no centro da imagem e pode movimentá-la, escolhendo para onde olhar, ele não tem a possibilidade de manipular o ambiente ou se mexer na cena, o que dá o controle da experiência a quem a editou (Domínguez, 2017; Doyle et., 2016; Jones, 2017). Dessa forma, Elmezeny et al. (2018) caracterizam esse espectador como um consumidor ativo ou um participante passivo.

Ainda no caso dos vídeos em $360^{\circ}$, alguns elementos são importantes de serem considerados na hora de se construir a interatividade. Se não há um alvo central em cena, as pessoas se sentem mais livres para explorar o ambiente, e assim movimentam mais a imagem e há uma maior interação com o conteúdo (Broeck et al., 2017; Jun et al., 2020; Wu et al., 2017). Outro aspecto relevante é o movimento da câmera. Se a imagem está em movimento, as pessoas também a giram mais, pois sempre há algo novo para ser visto. Se a câmera fica estática, há uma exploração inicial, mas depois de alguns instantes o espectador tende a focar em uma única área (Broeck et al., 2017). Por fim, Lin et al. (2017) apontam para o fato de que, quando a imagem gira automaticamente para focar no alvo central, fica mais fácil acompanhar o que está acontecendo, porém essa tática oferece menos liberdade de exploração se comparada com a estratégia de colocar uma dica visual ou sonora para orientar o espectador.

Experiências mais interativas do que os vídeos em $360^{\circ}$ mobilizam todo o corpo, pois assim o espectador pode participar da ação, controlando o seu avatar e modificando o ambiente virtual e o decorrer da história (Hardee, 2016; Ryan, 1999; Slater e Wilbur, 1997; Steuer, 1992). Para Ryan (1999), quando a pessoa tem o poder de agir sobre a narrativa (e não somente sobre o seu ponto de vista), ela se torna um ator no palco.

A interatividade é interrompida quando acontece a transição de uma cena para outra, o que causa confusão e frustração para o espectador que está ativamente explorando o ambiente. Para evitar isso, o corte precisa ser anunciado com alguma antecedência, com uma ação de alguém na imagem ou com uma mudança no som ambiente, por exemplo (Broeck et al., 2017; Domínguez, 2017).

$\mathrm{O}$ headset é o aparelho que proporciona maior interatividade. Apesar de causar algum desconforto pela falta de costume com a tecnologia, ele bloqueia todos os estímulos externos. Com o headset as pessoas podem movimentar a cabeça, o que dá mais naturalidade à interação, e, se acompanhado de um sistema de rastreamento de movimentos, também é possível manipular o avatar e os objetos na cena. Nos aparelhos móveis, o espectador pode mexer o corpo ou usar os dedos para rodar a imagem. Nas telas planas, como as dos computadores, é preciso utilizar o mouse, o que, apesar de ser mais familiar, dificulta a interação e não é mais um movimento tão natural (Broeck et al., 2017; Fox et al., 2009; Sundar et al., 2017; Watson, 2017). 


\section{Sensação de presença}

$\mathrm{Na}$ literatura, o conceito de presença remete ao espectador se sentir transportado para o mundo virtual. É como se a consciência da pessoa deixasse temporariamente o aqui e o agora e entrasse num novo universo, que está em outro tempo e espaço, onde há uma narrativa própria sendo desenvolvida, e o espectador se sentisse incluído nessa nova realidade (Hardee, 2016; Owen et al., 2015; Reis e Coelho, 2018; Ryan, 1999).

A RV dá a sensação de que não há a mediação tecnológica (apesar de ela existir), como se fosse quebrada a quarta parede, e por isso as pessoas sentem como se realmente estivessem presentes no ambiente virtual (Domínguez, 2017; Ryan, 1999). Slater e Wilbur (p. 604, 1997) afirmam que, "quando olhamos para uma tela de TV ou filme, é o mesmo que olhar através de uma janela, exceto que o cenário e os eventos que se desenrolam são tipicamente distantes no lugar e no tempo"; o que as tecnologias imersivas, como a RV, fazem é nos auxiliar a ultrapassar essa janela que nos distancia da realidade retratada, ficando mais perto da ação.

Para Slater (2009), o significado de presença pode ser dividido em duas partes: "Place Illusion" (PI) e "Plausibility Illusion" (Psi). A realização da PI, a sensação de estar presente no ambiente virtual, depende da "geração de contingências sensório-motoras pelo sistema de realidade virtual semelhantes aos da realidade física" (Peña et al., p. 294, 2010). Ou seja, para o espectador olhar para o lado, ele precisa mover a cabeça. Se ele quiser pegar algo, é necessário mover o braço. Por isso, quanto mais estímulos sensório-motores são comportados (audição, visão, tato, olfato etc.), e quanto mais eles forem naturais e semelhantes ao real, maior a sensação de presença (Hardee, 2016; Slater, 2009; Slater e Wilbur, 1997; Steuer, 1992).

A Psi é a ilusão de que o que está acontecendo no mundo virtual está realmente acontecendo, e com o próprio espectador: "Se você está lá e os eventos estão acontecendo, então eles estão acontecendo com você" (Peña et al., p. 295, 2010). Para que a Psi ocorra, o ideal é que tanto o ambiente quanto os outros seres presentes na RV se dirijam diretamente ao espectador ou respondam de acordo com as suas ações. Por isso é importante que as consequências sejam claramente reflexos das ações do consumidor e que tudo aconteça de forma natural (Elmezeny et al., 2018; Heeter, 1992; Slater, 2009). "Se os outros o reconhecem como estando no mundo virtual com eles e interagem com você, isso oferece mais evidências de que você existe" (Heeter, sp, 1992). Outra questão importante para a Psi é a presença de um avatar que represente o corpo do espectador, seja ele inteiro ou só uma parte, como os braços (Elmezeny et al., 2018; Heeter, 1992; Ryan, 1999; Slater e Wilbur, 1997).

Quando PI e Psi ocorrem conjuntamente, a pessoa se comporta como se realmente estivesse inserida no ambiente virtual e como se tudo o que está acontecendo fosse real (Hardee, 2016; Mabrook e Singer, 2019; Peña et al., 2010; Slater et al., 2009).

Outras características que ajudam a formar e aumentar a sensação de presença em RV são: o bloqueio dos estímulos externos (Reis e Coelho, 2018; Slater e Wilbur, 1997; Sundar et al., 2017; Witmer e Singer, 1998); o modo de produção do conteúdo, pois algumas práticas tradicionais do audiovisual, como cortes repentinos, zoom e fade-ins, normalmente não contribuem para a RV (Hardee, 2016); conteúdos de caráter emocional geram mais engajamento do público (Baños et al., 2005; Domínguez, 2017; Gorini et al., 2010); a qualidade dos estímulos oferecidos, principalmente o visual, o que é especialmente importante quando o conteúdo não tem caráter emocional (Domínguez, 2017; Nikolic, 2007; Slater et al., 2009; Sundar et al., 2017); colocar o espectador em primeira-pessoa (Laws, 2020; Steuer, 1992); e maiores níveis de interatividade e realismo (Comber et al., 2018; Nikolic, 2007; Ryan, 1999; Steuer, 1992).

Também é preciso ficar atento a algumas questões para evitar a quebra da sensação de presença: dicas visuais e auditivas são essenciais para que o espectador possa acompanhar a cena e não ser surpreendido com um corte (Broeck et al., 2017; Elmezeny et al., 2018); a equipe de produção e o material de gravação (elementos que não fazem parte da história) precisam ficar o mais invisível possível para o público (Foletto e Souza, 2019; Heeter, 1992; Kool, 2016); por fim, o aparelho e o vídeo não podem causar 
muito desconforto ou enjoo ao espectador, pois assim ele fica distraído e a sensação é prejudicada (Broeck et al., 2017; Witmer et al., 1998).

$\mathrm{Na}$ RV há uma escala na sensação de presença. Assim como acontece no caso da interatividade, ela é maior no headset (em especial se este estiver conectado com aparelhos que rastreiam o movimento), depois nos dispositivos móveis e por fim na tela plana de um computador (Gorini et al., 2010; Makransky et al,, 2019; Rupp et al., 2019; Sundar et al., 2017). Como consequência, quanto menos imersiva é a tecnologia, mais a sensação de presença depende da atenção, da cognição e do processo de imaginação do espectador. Isso não significa que, em meios que geram alta presença, o espectador não precise se entregar à narrativa. Pelo contrário, para se sentir presente no mundo virtual ele precisa se deixar levar pela história, acreditar no que está vendo e dar significado ao que está vivenciando. O que a tecnologia faz é acelerar esse processo, logo, é importante unir a parte técnica com as habilidades cognitivas do espectador (Hardee, 2016; Slater, 2009; Steuer, 1992; Witmer e Singer, 1998). Ryan (p.117, 1999) afirma que "alcançar a sensação de presença não é uma sujeição passiva ao texto, mas o resultado de uma atividade mental exigente".

\subsection{Realidade virtual no contexto da divulgação científica \\ Os desafios da divulgação científica}

As atividades de divulgação científica são normalmente baseadas no chamado "modelo do déficit". Isso significa que a comunicação impõe uma hierarquia na qual o cientista seria o detentor do conhecimento, enquanto o público é visto como um conjunto de pessoas "analfabetas científicas" que precisa ser educado. Em outras palavras, é uma comunicação unilateral feita de quem sabe para quem não sabe (Dieb e Peschanski, 2017; Moreira e Massarani, 2002). Esse modelo também tem uma visão positivista da ciência, o que significa que ela é vista como a verdade absoluta e não tem espaço para ser questionada (Capozoli, 2002).

A utilização do modelo do déficit na comunicação tem consequências na relação entre público e ciência. Burkett (1990) e Torres (2017) apontam para o fato de a figura do cientista (e o seu trabalho) estar afastada do imaginário popular. Já Capozoli (2002) e Moreira e Massarani (2002) ressaltam que a ciência e aqueles que a fazem são vistos de forma mistificada e espetacular, como se tivessem habilidades super-humanas.

Ao invés de deixar em evidência esse distanciamento por meio de uma prática hierárquica de comunicação, o papel da divulgação científica deve ser o de mediar o encontro e o diálogo entre ciência e público (Torres, 2017 e Valerio, 2012). Segundo Porto (p. 161, 2009), "a comunicação em ciência assume papel de duplicidade, além de servir como difusora de ciência ela possibilita o diálogo entre cientistas e sociedade, buscando criar um elo de circulação para a construção do conhecimento".

Para promover tal encontro, existem alguns desafios que perpassam o meio da divulgação da ciência. O primeiro deles é como traduzir a linguagem científica em algo que possa ser compreendido pelo público (Bueno, 1998), que não tem necessariamente uma formação técnica e/ou acadêmica na área e que não está familiarizado com seus jargões e conceitos (Bueno, 2010). Essa tradução enfrenta algumas barreiras, mas a principal delas está no fato de que entre o cientista e o público há uma nova figura, o comunicador (Burkett, 1990; Candotti, 2002; Teixeira, 2002). O papel do comunicador é justamente pegar o discurso técnico e transformá-lo em algo que possa ser consumido pela população, muitas vezes utilizando metáforas, analogias, ilustrações e simplificando conceitos complexos.

Existem pelo menos dois problemas nesse processo: os comunicadores, em grande parte, não têm conhecimento técnico suficiente para transmitir as informações de forma precisa, enquanto os cientistas não auxiliam na tradução do conhecimento para 
uma linguagem acessível, pois não abrem mão da precisão em favor de uma forma mais compreensível de se explicar um conceito (Bueno, 1998; Bueno, 2010; Burkett, 1990; Teixeira, 2002).

O segundo desafio é ultrapassar a lógica positivista da comunicação sobre ciência. Ou seja, ao invés de tratá-la como verdade absoluta e mostrar apenas os resultados pontuais e espetaculares das pesquisas, é preciso também contextualizar e apresentar um lado mais humano da ciência. Isso quer dizer mostrar os erros, os desafios, os riscos, as incertezas, os métodos, os processos (que em geral levam muito tempo) e ir além da simples tradução e exposição do conhecimento. A comunicação precisa ser crítica e contextualizar os impactos no cotidiano e no futuro da sociedade, sempre ajudando a construir sentidos e significados (Moreira e Massarani, 2002; Porto, 2009; Torres, 2017).

Para além desses dois potenciais problemas, Ebohon e Peschanski (p. 6, 2017) apontam para o fato de que a ciência tem "uma dificuldade de explorar e experimentar formas criativas e profundas de representar-se e representar seus processos", e precisa de mais diversidade na forma como se mostra ao público. Isso, inclusive, é uma demanda por parte dos consumidores de informação (Junior, 2009; Pinheiro et al., 2014).

\section{Realidade virtual e ciência}

Os meios digitais abriram novas possibilidades na comunicação, representando um jeito novo, mais criativo, colaborativo, interativo, diversificado, rápido e próximo de se apresentar conteúdos, inclusive o científico (Gonçalves, 2012; Junior, 2009; Porto, 2009; Valerio, 2012). No contexto da divulgação científica, os meios digitais permitem que o conhecimento seja de mais fácil acesso para o público, ultrapassando a barreira acadêmica. Eles também ampliaram as possibilidades de difundir a informação científica e ajudam a aproximar a sociedade do fazer ciência, mudando, assim, a relação entre conteúdo e consumidor (Gonçalves, 2010; Gonçalves, 2012; Torres, 2017; Valerio, 2012).

A realidade virtual é uma tecnologia nesse âmbito digital que pode contribuir para a comunicação da ciência, endereçando justamente os problemas apontados acima. Embora tenha sido encontrado apenas um estudo que relaciona diretamente a divulgação científica e a RV (Foletto e Souza, 2019), pesquisas nos campos do jornalismo (mencionadas anteriormente) e da educação revelam este potencial há alguns anos, principalmente por conta do caráter imersivo da RV, que oferece uma forma mais criativa e direta de conectar o público com a ciência.

Nas pesquisas sobre RV e educação, são listados os seguintes benefícios dessa tecnologia: ela permite a simulação de espaços de difícil ou impossível acesso, como cidades antigas ou o interior do corpo humano (Allcoat e Mühlenen, 2018; Mikropoulos e Natsis, 2011; Pan et al., 2006; Rupp et al., 2019); ela possibilita o treinamento de habilidades que podem ser transferidas para o dia a dia, já que a pessoa se comporta como se a RV fosse real (Mikropoulos e Natsis, 2011; Rupp et al., 2019); ela transforma conceitos complexos e abstratos em um material mais tangível e compreensível (Mikropoulos e Natsis, 2011; Pan et al., 2006); ela auxilia na memorização do conteúdo (Allcoat e Mühlenen, 2018; Rupp et al., 2019); ela incentiva a colaboração (Mikropoulos e Natsis, 2011; Pan et al., 2006); ela conecta o aluno de forma mais emocional com o conteúdo (Allcoat e Mühlenen, 2018; Filter et al., 2020; Pan et al., 2006; Rupp et al., 2019); e, por fim, ela também ajuda a despertar o interesse por questões científicas - o que é o primeiro passo no processo de aprendizagem (Filter et al., 2020; Mikropoulos e Natsis, 2011; Pan et al., 2006; Rupp et al., 2019).

Note-se que algumas pesquisas não apontam benefícios significativos da RV para o aprendizado. Estudos indicam que: a tecnologia cria uma distração (Makransky et al., 2019; Mikropoulos e Natsis, 2011); existe uma dificuldade de navegação, o que atrapalha o aprendizado (Mikropoulos e Natsis, 2011; Pan et al., 2006); o interesse criado é pontual e não gera um conhecimento 
mais aprofundado sobre o tema (Makransky et al., 2019); o ambiente virtual não é capaz de substituir a sala de aula (Mikropoulos e Natsis, 2011); e dificulta o aprendizado e o processo de reflexão (Makransky et al., 2019).

\section{Metodologia}

A metodologia utilizada neste artigo é uma abordagem qualitativa, consistindo em uma pesquisa bibliográfica sobre RV, e um estudo de caso (Yin, 2001) de vídeos 360 graus de divulgação científica, tema que é contemporâneo, mas ainda pouco explorado no âmbito acadêmico. Dessa forma, em um primeiro momento, foram identificados, por meio da literatura, quais são os elementos necessários para criar imersão nesse tipo de produção audiovisual e, a partir disso, foi criada uma ficha de análise. Em seguida, foi feita uma coleta no YouTube de vídeos de divulgação científica feitos com a tecnologia da RV. A escolha por esse objeto de estudo se deu, justamente pelo fato da RV mostrar potencial para ampliar e diversificar as atividades científicas, educacionais e de comunicação. A partir dessas etapas (apresentadas em mais detalhes a seguir), foi possível realizar uma descrição detalhada a fim de verificar como tais critérios estavam presentes nos vídeos analisados.

\subsection{Critérios para a análise dos vídeos}

Como foi visto, o realismo, a interatividade e a sensação de presença são essenciais para que a experiência em realidade virtual seja imersiva. Com base na sistematização da literatura, identificamos treze critérios específicos para analisar em que medida essas três dimensões da RV são realizadas, especialmente nos vídeos em $360^{\circ}$. Os critérios estão descritos e justificados nas Tabelas 1,2 e 3 , apresentadas abaixo.

Tabela 1: Critérios de realismo em vídeos 360 graus.

\begin{tabular}{|c|c|}
\hline \multicolumn{2}{|c|}{ Realismo } \\
\hline Pergunta & Teoria por trás do critério \\
\hline Em que medida o som é surround? & $\begin{array}{l}\text { Assim como na vida real, o som deve mudar conforme a posição do } \\
\text { espectador (Domínguez, 2017; Fox et al., 2009; Slater e Wilbur, 1997) }\end{array}$ \\
\hline Qual é a qualidade da imagem? & $\begin{array}{c}\text { Quanto melhor a qualidade da imagem, mais nítido fica o ambiente, e } \\
\text { menos a tecnologia fica aparente. Se a imagem é muito pixelada, por } \\
\text { exemplo, o ambiente não é mais tão realista (Slater e Wilbur, 1997; } \\
\text { Steuer, 1992) }\end{array}$ \\
\hline $\begin{array}{l}\text { Videos filmados com câmeras } 360 \text { : Quantos elementos artificiais foram } \\
\text { inseridos no vídeo? Como e com que frequência eles são utilizados? }\end{array}$ & $\begin{array}{l}\text { Elementos artificiais, que não pertencem ao ambiente e são inseridos na } \\
\text { pós-produção, como gráficos e textos, quebram a sensação de realismo } \\
\text { (Kool, 2016; Lin et al., 2017) }\end{array}$ \\
\hline Vídeos feitos com animação: Como são os detalhes do vídeo? & $\begin{array}{l}\text { Quanto mais detalhes são adicionados à animação, mais realista fica o } \\
\text { ambiente. Se o espectador está em um quarto, por exemplo, é } \\
\text { interessante colocar mais do que uma cama no cômodo (Christou e } \\
\text { Parker, 1995; Slater e Wilbur, 1997; Van Gisbergen et al., 2019) }\end{array}$ \\
\hline $\begin{array}{l}\text { Vídeos feitos com animação: Como é construída a verossimilhança na } \\
\text { animação? A imagem é verossímil o tempo inteiro ou há momentos e/ou } \\
\text { detalhes que destoam do resto? }\end{array}$ & $\begin{array}{l}\text { Quanto mais próxima a animação for de algum correspondente no } \\
\text { mundo real, mais realista é a experiência. Para isso, é preciso levar em } \\
\text { consideração alguns fatores, como luz/sombra, textura, tons de cor, } \\
\text { perspectiva, campo de visão e proporção. Se há algum elemento que } \\
\text { destoa do restante, o realismo é prejudicado (Christou e Parker, 1995; } \\
\text { Domínguez, 2017; Nikolic, 2007; Slater et al., 2009; Slater e Wilbur, } \\
\text { 1997; Van Gisbergen et al., 2019) }\end{array}$ \\
\hline $\begin{array}{l}\text { Videos feitos com animação: Como o ambiente e os elementos se } \\
\text { comportam? }\end{array}$ & $\begin{array}{l}\text { Não é apenas importante que o ambiente pareça real, mas que os } \\
\text { elementos e personagens também se comportem de forma natural para } \\
\text { que a experiência seja realista (Christou e Parker, 1995; Nikolic, 2007; } \\
\text { Slater et al., 2009) }\end{array}$ \\
\hline
\end{tabular}

Fonte: Autores (2021). 
Tabela 2: Critérios de interatividade em vídeos 360 graus.

\begin{tabular}{|c|c|}
\hline \multicolumn{2}{|c|}{ Interatividade } \\
\hline Pergunta & Teoria por trás do critério \\
\hline $\begin{array}{c}\text { Como o vídeo focaliza a atenção do espectador? Ele utiliza alvos } \\
\text { centrais? }\end{array}$ & $\begin{array}{c}\text { Quando há um alvo central (seja pessoa, animal, objeto ou lugar), o } \\
\text { espectador tende a focar nisso e não explora tanto o entorno (Broeck et } \\
\text { al., 2017; Jun et al., 2020; Wu et al., 2017) }\end{array}$ \\
\hline Como é o movimento da câmera/imagem no vídeo? & $\begin{array}{c}\text { Quando a câmera ou a imagem está em movimento, sempre há novos } \\
\text { elementos na tela para explorar, com isso, o espectador tende a } \\
\text { movimentar mais seu o ângulo de observação do vídeo (Broeck et al., } \\
\text { 2017) }\end{array}$ \\
\hline $\begin{array}{c}\text { Como o vídeo utiliza a rotação automática da imagem para centralizar a } \\
\text { visão em uma área específica? }\end{array}$ & $\begin{array}{c}\text { Quando a imagem roda automaticamente para focar em um ponto } \\
\text { especíco, o espectador tende a não explorar o entorno e deixa esse } \\
\text { mecanismo guiar para onde ele deve olhar (Lin et al., 2017) }\end{array}$ \\
\hline
\end{tabular}

Fonte: Autores (2021).

Tabela 3: Critérios de sensação de presença em vídeos 360 graus.

\begin{tabular}{|c|c|}
\hline \multicolumn{2}{|c|}{ Sensação de presença } \\
\hline Pergunta & Teoria por trás do critério \\
\hline Como é a interação com o espectador? & $\begin{array}{l}\text { O espectador se sente mais presente na cena quando alguém ou algum } \\
\text { elemento do ambiente reconhece que ele está ali, que ele também faz } \\
\text { parte da história (Elmezeny et al., 2018; Heeter, 1992; Slater, 2009) }\end{array}$ \\
\hline Em que medida o conteúdo é emocional? & $\begin{array}{l}\text { Quando o conteúdo tem caráter emocional, é mais fácil para o } \\
\text { espectador se sentir presente na cena (Baños et al., 2005; Domínguez, } \\
\text { 2017; Gorini et al., 2010) }\end{array}$ \\
\hline Como é a representação do espectador no vídeo? & $\begin{array}{l}\text { Quando há um avatar representando o espectador na cena, ele se sente } \\
\text { mais presente naquele ambiente (Elmezeny et al., 2018; Fox et al., 2009; } \\
\text { Heeter, 1992; Ryan, 1999; Slater, 2009; Slater e Wilbur, 1997) }\end{array}$ \\
\hline $\begin{array}{c}\text { Como a equipe de produção e/ou os equipamentos de gravação estão } \\
\text { visíveis? }\end{array}$ & $\begin{array}{l}\text { Quando elementos que não fazem parte do ambiente ficam visíveis, } \\
\text { como um tripé ou um produtor, a sensação de se estar presente é } \\
\text { prejudicada, pois a mediação fica aparente (Foletto e Souza, 2019; } \\
\text { Heeter, 1992; Kool, 2016) }\end{array}$ \\
\hline
\end{tabular}

Fonte: Autores (2021).

\subsection{Definição e busca do objeto de estudo}

A fim de mostrar como os critérios descritos acima podem ser usados na hora de se analisar e produzir conteúdos imersivos em RV, este artigo selecionou vídeos de divulgação científica em português feitos em $360^{\circ}$. Todos os vídeos trabalhados no artigo estão disponíveis no YouTube. A escolha pela plataforma se dá pelo fato de que a mesma disponibiliza a opção de vídeos em realidade virtual desde 2015, o que proporciona uma maior base para a busca desse tipo de material. Além disso, ele é acessível ao público em geral, que muitas vezes não tem um aparelho específico de RV.

Foram utilizados dois métodos de busca com o objetivo de coletar a maior quantidade possível de vídeos. Inicialmente foi feita a pesquisa a partir da ferramenta de busca do próprio YouTube. Nessa investigação, que ocorreu em 24 de maio de 2021, foram usados como base os termos "vídeo", "360" e "ciência", com a seleção do filtro $360^{\circ}$. Dentre as centenas de resultados da busca, a pesquisa retornou 24 vídeos que se encaixavam no objeto de estudo. No entanto, esse método apresentou três problemas: a maior 
parte dos resultados foi de produções em uma língua diferente e que não eram de divulgação científica; a busca não ofereceu os mesmos resultados todas as vezes, por isso, se ela for realizada em uma outra data, alguns vídeos podem não estar listados e outros podem aparecer; além disso, por esse método, nem todas as produções ligadas à ciência feitas em 360 são apresentadas nos resultados.

Para complementar a pesquisa anterior, foi realizada uma coleta por meio da ferramenta de API disponibilizada pelo Google, entre 14 e 17 de maio. A partir dela foi possível fazer um levantamento em todo o YouTube através de alguns comandos. Foram selecionadas como base para a busca as categorias "Educação", "Ciência \& Tecnologia" e "Notícias \& Política", pois, dentre todas as opções disponíveis na API, elas são as que mais se relacionavam com a área de divulgação científica. Em cada uma foi feita uma pesquisa de vídeos com as seguintes características: disponíveis no Brasil, em português, com as palavras "360" e "realidade virtual" no título (no caso de "Notícias \& Política", foi adicionada a palavra "ciência"). Foram encontrados 315 vídeos na busca, dos quais nove atendiam aos critérios do objeto de estudo. É importante notar que mesmo utilizando esse método de coleta mais amplo, nem todos os vídeos da plataforma que se encaixavam nos parâmetros foram selecionados, pois o uso das palavras-chaves restringiu a quantidade de resultados retornados. Além disso, existem outras produções classificadas em categorias diferentes, como "Pessoas \& Blogs" e "Entretenimento".

Dentre os 24 resultados obtidos a partir da busca direta no YouTube e os nove que vieram por meio do API, cinco deles se repetiram nas duas listas. Com isso, o total de vídeos analisados neste artigo é de 28. A lista completa de todos os vídeos analisados está disponível na Tabela 4, que conta com o nome de cada um dos vídeos, o nome do canal que o publicou, a data da postagem no YouTube, a duração de cada um e o link em que estão disponíveis.

Tabela 4: Vídeos $360^{\circ}$ de divulgação científica coletados do YouTube.

\begin{tabular}{|c|c|c|c|c|}
\hline Nome do vídeo & Nome do canal & Data de publicação & Duração & Link \\
\hline 1. O fascínio das plantas em investigação científica & IGCiencia & $18 / 05 / 2021$ & 2:59 & https://www.youtube.com/watch?v=r5_EGMW3zaw \\
\hline 2. A história das plantas & Jardim Botânico de Brasília JBB & $17 / 05 / 2021$ & $3: 54$ & https://www.youtube.com/watch?v=HKWlC98VndY \\
\hline 3. O Cerrado do Jardim Botânico de Brasília & Jardim Botânico de Brasília JBB & $17 / 05 / 2021$ & $7: 14$ & https://www.youtube.com/watch?v=fyiSufeJwaE \\
\hline 4. A Permacultura no JBB & Jardim Botânico de Brasília JBB & $03 / 05 / 2021$ & 4:08 & https://www.youtube.com/watch?v=WjS5Lzyqtoo \\
\hline 5. Tour Virtual em Realidade Virtual | Grupo Águas do Brasil & Agência Casa Mais & $29 / 03 / 2021$ & $7: 41$ & https: $/ /$ www.youtube.com/watch?v=7mcBSeZIhM0 \\
\hline 6. $[$ Video 360$]$ - Sistema Solar & Humor Quântico & $13 / 03 / 2021$ & $9: 49$ & https://www.youtube.com/watch?v=aY4N7_O5aO0 \\
\hline 7. [Vídeo 360$]$ - Como nascem as estrelas & Humor Quântico & $18 / 08 / 2020$ & $6: 14$ & https://www.youtube.com/watch?v=cnJQg-j3TLE \\
\hline 8. NeuroMat em $360^{\circ}$ : assinaturas do cérebro (realidade virtual) & NeuroMat & $29 / 07 / 2020$ & $12: 22$ & https: //www.youtube.com/watch?v=oEtNBNAPzp8 \\
\hline 9. Linhas Paralelas Podem Se Encontrar No Fim Do Universo $\mid 360$ RV & INCRÍVEL & $16 / 06 / 2020$ & $8: 18$ & https://www.youtube.com/watch?v=sMDIP47DOKk \\
\hline 10. Astronomia no Brasil - 360 & Felipe Carelli & $28 / 04 / 2020$ & $4: 44$ & https://www.youtube.com/watch?v=RYkKzE78c9c \\
\hline 11. Encontro de Jovens Cientistas do NeuroMat em 360 Graus & NeuroMat & $13 / 02 / 2020$ & $1: 25$ & https://www.youtube.com/watch?v=yic6zQwPetU\&t=2s \\
\hline 12. Cerrado sensu stricto: Tour virtual 360 (Compatível VR) & Doutor ciências & $15 / 10 / 2019$ & 2:55 & https://www.youtube.com/watch?v=h8sZ4tRpJzw \\
\hline 13. A circulação sanguínea -360 & Hemocentro RP & $29 / 05 / 2019$ & $3: 20$ & https://www.youtube.com/watch?v=c6b3eNHgaYg \\
\hline 14. Video 360 Pegadas de Dinossauro Praia Santa (Portugal) & Ciência Viva Lagos & $08 / 02 / 2019$ & $0: 40$ & https://www.youtube.com/watch?v=ILIHypbyTDI \\
\hline 15. Visita em 360 | Ourofino Agrociência & Ourofino Agrociência & $30 / 08 / 2018$ & $3: 54$ & https://www.youtube.com/watch?v=yiOOCdQ9FiE \\
\hline 16. Giro Ciência | Giro Saúde - Gripe (Para óculos VR) & Giro Ciência & $02 / 07 / 2018$ & $3: 46$ & https://www.youtube.com/watch?v=I9RpWpyzW1I \\
\hline 17. O que acontece dentro do seu corpo? $\| 360 \mathrm{VR}$ & INCRÍVEL & $12 / 06 / 2018$ & 9:02 & https://www.youtube.com/watch?v=XN6GsVRHnhM \\
\hline 18. Marte: O planeta vermelho em $360^{\circ}$ ! & Guru da Ciência & $26 / 05 / 2018$ & $11: 30$ & https://www.youtube.com/watch?v=7kSm291X_ho \\
\hline 19. Raio-x do universo em $360^{\circ} !$ & Guru da Ciência & $15 / 04 / 2018$ & 11:17 & https://www.youtube.com/watch?v= OmCKSwiFYw \\
\hline 20. Ciência e Tecnologia no café - realidade virtual & Embrapa & $06 / 11 / 2017$ & $3: 18$ & https://www.youtube.com/watch?v=MzOr9eG74KU \\
\hline 21. Exploração do Sistema Solar 360: Parte V - Vênus & Mensageiro Sideral & $20 / 06 / 2017$ & $5: 57$ & https://www.youtube.com/watch?v=teuKoDMXOto \\
\hline 22. Sons do Sistema Solar em $360^{\circ} !$ & Guru da Ciência & $28 / 05 / 2017$ & $4: 22$ & https://www.youtube.com/watch?v=LVI55mSmXo4 \\
\hline 23. Fractal em 360 graus & Ciência Sem Limites & $28 / 03 / 2017$ & $0: 40$ & https: $/ /$ www.youtube.com/watch?v=UptMd9TbaQ0 \\
\hline 24. Entrando em um fractal! $\left(360^{\circ}\right)$ & Guru da Ciência & $01 / 02 / 2017$ & 2:00 & https://www.youtube.com/watch?v=sBcM87hZVH4 \\
\hline 25. Missão pré-sal - Vídeo 360 & Petrobras & $25 / 10 / 2016$ & $6: 10$ & https://www.youtube.com/watch?v=D1-4vKR7a28 \\
\hline 26. Na Real Educação imersiva | Vídeo 360 Realidade Virtual & Tecnologia Educacional & $27 / 07 / 2016$ & $1: 49$ & https://www.youtube.com/watch?v=ImXRZSO8DRY \\
\hline 27. Entrando em um buraco negro! $\left(360^{\circ}\right)$ & Guru da Ciência & $25 / 06 / 2016$ & $3: 01$ & https://www.youtube.com/watch?v=Un-WjxdjtRc \\
\hline 28. Você é a interface no novo mundo da realidade virtual & UOL TAB & $19 / 06 / 2016$ & $6: 45$ & https://www.youtube.com/watch?v=Q0ahFo268Wg \\
\hline
\end{tabular}

Fonte: Autores (2021). 


\section{Resultados e Discussão}

Uma vez tendo os critérios de imersão e os vídeos em 360 graus de divulgação científica selecionados, fizemos uma análise da construção do realismo, da interatividade e da sensação de presença nessas produções.

\section{Realismo}

Em que medida o som é surround?: Não houve variação na análise. Em nenhum dos casos analisados a produção optou por utilizar o som surround. Enquanto todos poderiam ter explorado essa técnica, um exemplo que chama a atenção é o caso do vídeo 22, justamente pelo fato do som ser o tema central.

Qual é a qualidade da imagem?: Houve grande variação na análise. Os vídeos de número 2, 3 e 4 foram filmados mais recentemente e têm resolução 2880p (5K) - a maior disponível na plataforma. Já os vídeos 5 e 14, por exemplo, têm resolução um pouco menor, de 2160p, mas também apresentam ótima qualidade. As animações 13, 18, 19 e 27 também foram produzidas em 2160p (4K) e têm uma boa resolução. Nesses nove casos, se o espectador tiver uma boa conexão com a internet, a imagem na tela ficará nítida e sem pixels aparentes, pois a qualidade técnica da produção e da publicação são as melhores possíveis.

Por outro lado, a animação do vídeo 6, mesmo estando em 2160p (4K), tem uma imagem mais pixelada independentemente da conexão com a internet. Já os vídeos 1, 16 e 28 estão disponíveis em 1080p (HD), o que significa que a resolução, apesar de ser boa, não é tão nítida como as dos vídeos citados acima. Com isso, nesses quatro exemplos, a imagem fica mais pixelada e a tecnologia está aparente.

Vídeos filmados com câmeras $360^{\circ}$ - Quantos elementos artificiais foram inseridos no vídeo? Como e com que frequência eles são utilizados?: Houve pouca variação na análise, pois a maior parte dos vídeos feitos com câmeras $360^{\circ}$ possui elementos artificiais em tela, mas o grau em que isso é feito e quais elementos são inseridos variam. Nos vídeos 5 e 16, por exemplo, são utilizados gráficos e textos em alguns momentos para ajudar a ilustrar o que o narrador está falando. No caso dos vídeos 8 e 10 , há o uso de textos para passar informações ou identificar as pessoas que aparecem na tela, enquanto nos vídeos 16 e 26 são usados elementos artificiais para destacar determinados objetos/áreas que são importantes à narrativa. Os vídeos 12 e 14 são dois raros exemplos da não inserção de elementos artificiais na produção.

Embora em menor escala, também existem alguns casos de animações que optam por utilizar elementos que, teoricamente, não pertencem ao cenário criado, como é o caso do vídeo 18. Além da animação com a vista do planeta Marte, o autor também utiliza fotos, mapas e desenhos para ilustrar suas falas, elementos que não fazem parte do desenho principal.

Vídeos feitos com animação - Como são os detalhes do vídeo?: Houve pouca variação na análise, pois os vídeos em animação analisados apresentam alto grau de detalhamento de forma geral. Esse é o caso dos vídeos 19 e 22, por exemplo. Em ambas as produções há uma preocupação em preencher todo o espaço disponível, e as imagens apresentam minúcias que ajudam a construir o ambiente de forma realista. No vídeo 22 é possível ver a superfície dos planetas, as estrelas no entorno, os satélites que os cercam e a diferença na velocidade de rotação no próprio eixo e ao redor do Sol.

O que foi observado em alguns casos, como nos vídeos 9 e 24, é o fato de que alguns elementos possuem um alto grau de detalhamento, enquanto outros não contam com a mesma preocupação com os detalhes. Se compararmos os vídeos 23 e 24, essa diferença fica clara. Ambos mostram o que é um fractal, porém, enquanto todos os ângulos do 23 são preenchidos com detalhes dessa figura geométrica, no 24 o fractal é muito detalhado, mas o restante do espaço é composto apenas por um fundo azul, branco e verde. 
Vídeos feitos com animação - Como é construída a verossimilhança na animação? A imagem é verossímil o tempo inteiro ou há momentos e/ou detalhes que destoam do resto?: Houve grande variação na análise. Em geral, a verossimilhança dos vídeos analisados não é consistente durante todo o tempo, ou então falha em um dos aspectos importantes para uma construção de uma cena mais realista - jogo de luz/sombra, textura, tons de cor, perspectiva, campo de visão e proporção. No vídeo 21, por exemplo, a imagem de Vênus vista do espaço é verossímil, mas, quando ela mostra o solo venusiano, a qualidade de resolução é menor e os detalhes menos trabalhados, o que prejudica a verossimilhança. Já no vídeo 17, um dos elementos que ajudam a criar verossimilhança é falho, pois falta textura nas imagens sobre o interior do corpo humano - as superfícies sempre parecem lisas. Por outro lado, o vídeo 22 se destaca por ter consistência na verossimilhança e apresentar os seis elementos essenciais para a construção da mesma.

Vídeos feitos com animação - Como o ambiente e os elementos se comportam?: Houve alguma variação na análise. No vídeo 27 , no qual há a simulação de um buraco negro, o comportamento do ambiente não se assemelha completamente ao que se sabe que sobre a dinâmica de como os buracos negros funcionam no mundo real, o que pode atrapalhar o realismo da experiência. Em contrapartida, no vídeo 22, que também tem como temática o ambiente do espaço, há uma preocupação para que o movimento dos planetas, dos satélites, do sol e das sombras seja natural e muito semelhante ao real. Ou seja, é possível ver a rotação diferente de cada planeta, as sombras mudando de acordo com a posição em relação ao sol e os satélites fazendo suas órbitas, assim como esses elementos se comportam normalmente, o que faz a produção ser mais realista.

Um caso interessante de analisar é o do vídeo 13. Logo na primeira cena há uma animação de uma mulher correndo, o que, ao bater o olho, é um comportamento usual. No entanto, ao observar mais atentamente, é possível perceber que os movimentos, apesar de serem muito semelhantes ao que acontece no mundo real, não apresentam o mesmo nível de detalhamento e precisão. Enquanto ela corre parece não haver impacto com o chão, por exemplo, e isso pode prejudicar o nível de naturalidade e de realismo da animação, embora não atrapalhe a ponto de tornar a cena inverídica.

\section{Interatividade}

Como o vídeo focaliza a atenção do espectador? Ele utiliza alvos centrais?: Houve grande variação na análise. Os vídeos 4 e 7 são exemplos de como a presença de um alvo central diminui a exploração dos diversos ângulos e assim diminui a interatividade. No caso do número 7, todas as informações sobre o nascimento das estrelas estão em forma de texto, que são o ponto central de focalização. Dessa forma, se o espectador movimenta a imagem, ele corre o risco de perder uma das informações. No caso do vídeo 4, o apresentador e as informações visuais mais importantes ficam sempre ocupando um único ponto da tela, com isso, não há incentivo para o espectador explorar o restante do ambiente.

Já no caso dos vídeos 3 e 10, apesar dos apresentadores aparecerem na tela em diversos momentos, eles não são o alvo central. Eles, na verdade, incentivam o público a olhar o que está à sua volta, como os detalhes da vegetação, no caso do primeiro, e diferentes espaços ligados à astronomia no segundo.

Vale ressaltar que existem vídeos que intercalam momentos em que há ou não um alvo central em cena. Um exemplo é o 26, que fala sobre a dengue. Existem instantes nos quais o espectador é convidado a explorar o ambiente e olhar tudo ao redor, enquanto em outros momentos o narrador pede que a atenção seja voltada a áreas específicas do vídeo. Esse movimento incentiva a interatividade com o conteúdo.

Como é o movimento da câmera/imagem no vídeo?: Houve grande variação na análise. Dois exemplos de vídeos que não fazem uso do movimento da câmera são o número 1, que a coloca em um único ângulo da sala durante todo o tempo, e o número 
11, que até muda o posicionamento da câmera em alguns instantes, mas sempre dentro do mesmo ambiente. Nos dois casos fica claro que essa técnica, somado ao fato de ambos serem filmados em espaços fechados, desincentiva o espectador a explorar a imagem. O oposto acontece no vídeo 6, no qual o ponto de vista está sempre em movimento. Durante o passeio pelo Sistema Solar, o espectador precisa interagir com a imagem para conseguir observar todos os elementos que vão aparecendo à sua volta.

Também existem casos cujo a movimentação é feita de forma que atrapalha a experiência ou não acrescenta em nada. No vídeo 12, o espectador é levado para conhecer o cerrado brasileiro, porém, a pessoa que carrega a câmera tem movimentos muito instáveis, o que pode gerar desconforto para quem está assistindo (em especial no headset). Como visto anteriormente, se isso acontece, a experiência em RV fica prejudicada. Já no vídeo 25, a movimentação pouco contribui para a interatividade, pois toda a informação está concentrada em uma única parte da tela, enquanto o restante do espaço é ocupado pela máquina que leva o espectador pelo fundo do mar. Ou seja, mesmo que a imagem esteja em movimento, a pessoa não precisa não é motivada a mudar seu ângulo de visão.

Como o vídeo utiliza a rotação automática da imagem para centralizar a visão em uma área específica?: Houve pouca variação na análise. Dentre os oito vídeos que têm rotação automática, um caso chama mais atenção. No vídeo 9 , se o espectador nunca movimentar a tela, ele sempre vai ter a informação central focalizada, apesar do vídeo ter muito movimento de câmera. Isso acontece porque a imagem está sempre rodando automaticamente para manter as ilustrações no centro. Somado ao fato de que praticamente todos os detalhes estão concentrados em um único ponto da tela, o espectador não tem motivo para interagir e explorar os diversos ângulos, pois o espaço 360 é subaproveitado. Outro vídeo que faz bastante uso da rotação automática é o 17. Embora em grau menor do que o caso anterior, nesse vídeo também existem momentos em que o espectador não precisa mover a imagem para explorar o entorno, pois há a rotação automática.

Nos vídeos 8 e 28 não é utilizada a rotação automática, porém são usadas estratégias durante a fala e as movimentações em cena que ajudam a guiar o olhar do espectador, mas o deixam fazer a rotação sozinho. Essa técnica também dá liberdade para que ele explore todos os ângulos que desejar sem nenhuma interferência.

\section{Sensação de presença}

Como é a interação com o espectador?: Houve grande variação na análise. Dentre todos os vídeos, o 28 é o que tem maior interação com o espectador, pois a apresentadora e os personagens, em diversos momentos, falam diretamente com ele e agem como se a pessoa também estivesse presente naquele ambiente. Já nos vídeos 10 e 15, os cientistas e apresentadores falam diretamente com a câmera, como se o espectador estivesse na sua frente.

Em diversas produções é o narrador quem fala diretamente com a pessoa que está assistindo. O vídeo 26 é um bom exemplo disso. O narrador se direciona ao espectador em vários momentos e o incentiva a olhar ao seu redor. Em outros casos, como no 12 e no 25, o narrador se dirige ao público em momentos pontuais, como no início ou no final do vídeo. No entanto, como o narrador em si não está presente nos vídeos, ainda não existem evidências de que esse elemento em particular contribui ou não na sensação de presença.

Além disso, existem produções em que não há nenhum tipo de interação com espectador, como acontece nos vídeos 14, 21 e 27. No caso do 14 e do 27, não há nem mesmo uma narração. O 14 é apenas uma pessoa andando com uma câmera em um sítio arqueológico, enquanto o 27 é uma animação sobre buracos negros. 
Em que medida o conteúdo é emocional?: Houve pouca variação na análise, afinal o único vídeo que trabalha com a questão emocional é o 28. Nele a apresentadora fala sobre o que é considerado realidade, e coloca o espectador em ambientes construídos para gerar desconforto psicológico e evocar sensações como ansiedade e medo.

O fato de muitos dos vídeos terem caráter institucional, como é o caso dos números 11 e 20, ou trabalharem com temas educativos, como o 23 e o 24, que apenas apresentam o que é um fractal, fazem com que eles não tenham um conteúdo que evoque emoções.

Como é a representação do espectador no vídeo?: Houve pouca variação na análise. Apenas o vídeo 7 trabalha com a representação do espectador. Nele a pessoa assume o ponto de vista de um astronauta, e ao olhar para trás ou para baixo é possível ver um traje espacial que a representa, embora ela não consiga movimentá-lo pela limitação da plataforma. Já no vídeo 6 não há a representação física do espectador, mas ele é colocado do ponto de vista do piloto da espaçonave.

Um vídeo que poderia ter feito uso da representação do espectador, mas não o fez, é o 25, no qual a pessoa é levada para um passeio no fundo do mar. Seria interessante, por exemplo, representá-la com um avatar em roupa de mergulho, mas essa escolha não foi feita no momento da produção e da edição.

Como a equipe de produção e/ou os equipamentos de gravação estão visíveis?: Houve variação na análise. Em alguns casos, como nos vídeos 2, 5 e 15, por exemplo, é possível ver que houve a preocupação em esconder os equipamentos e a equipe de produção do resultado final. Isso é resultado de um planejamento tanto na hora de gravar o material, escondendo ao máximo os elementos técnicos que não pertencem ao ambiente, quanto no momento da edição, etapa na qual é possível apagar alguns elementos da imagem, como o tripé.

Já em outros vídeos, como o 8, o 16 e o 20, existem momentos em que a equipe e os equipamentos, como drones, câmeras e apoios para a câmera ficam visíveis. No caso do vídeo 16, além do tripé estar na cena, a câmera fica visível, pois a junção das duas imagens em 180 graus foi falha, deixando um espaço preto entre elas.

\section{Considerações Finais}

Os elementos necessários para a imersão do espectador no conteúdo em realidade virtual, especialmente vídeos em 360 graus, incluem o realismo, a interatividade e a sensação de presença. O realismo está relacionado à verossimilhança, riqueza de detalhes e informações, naturalidade e multiplicidade de estímulos sensoriais e motores no produto audiovisual. O realismo pode ser avaliado de acordo com seis critérios, abrangendo som, qualidade da imagem, presença de elementos artificiais, detalhes, consistência e fidedignidade. A interatividade é o principal aspecto da realidade virtual, pois garante um papel ativo ao espectador. São elementos interativos a multissensorialidade, a velocidade e correspondência de resposta na RV e a variedade no repertório de ação. A interatividade pode ser avaliada de acordo com três critérios: focalização, movimento e rotação. A sensação de presença diz respeito às formas pelas quais o espectador se sente incluído na RV, com especial relevância para a consolidação de uma ilusão plausível. Esse elemento pode ser avaliado de acordo com quatro critérios: interação e representação do espectador, emoção e percepção da produção.

Os critérios de realismo, interatividade e sensação de presença foram utilizados para analisar 28 vídeos $360^{\circ}$ de divulgação científica, disponíveis no YouTube em português. Na área de divulgação científica, há especial interesse em RV, por ser uma forma de aproximar o público da prática científica. A análise serviu para verificar as variações entre os produtos audiovisuais e testar o método de avaliação de vídeos proposto. Verificou-se que há grande variação entre os vídeos no modo como lidaram com as potencialidades da RV e que há grande variação no repertório de RV utilizado em cada vídeo. 
A variação sugere a relevância de seguir a pesquisa em busca de uma tipologia de vídeos $360^{\circ}$, para identificar as causas e consequências das diferentes estratégias relacionadas ao realismo, interatividade e sensação de presença nesse tipo de produto. Ainda são necessárias mais pesquisas para verificar se outros fatores também influenciam na questão da imersão em RV, e, a partir disso, eles poderão ser incorporados nos critérios de análise apresentados. Também se mostra relevante realizar mais estudos para verificar como outros produtos de comunicação (sejam eles científicos ou não) estão utilizando tais critérios para construir as narrativas. Já no campo científico, ainda é preciso explorar com maior profundidade o impacto das tecnologias de RV na transmissão e difusão do conhecimento.

\section{Agradecimentos}

Este artigo resulta das atividades de pesquisa realizadas no contexto do Centro de Pesquisa, Inovação e Difusão em Neuromatemática (NeuroMat), financiado pela Fundação de Amparo à Pesquisa do Estado de São Paulo (FAPESP, projeto 2013/07699-0). Agradecemos também a Éder Porto e Silvana Kobayashi pelo apoio técnico.

\section{Referências}

Allcoat, D., \& Mühlenen, A. von. (2018). Learning in virtual reality: Effects on performance, emotion and engagement. Research in Learning Technology, $26,13$.

Baños, R. M., Botella, C., Alcañiz, M., Liaño, V., Guerrero, B., \& Rey, B. (2005). Immersion and emotion: Their impact on the sense of presence. Cyberpsychology \& Behavior, 7(6), 734-741.

Broeck, M. V. den, Kawsar, F., \& Schöning, J. (2017). It's All Around You: Exploring 360 Video Viewing Experiences on Mobile Devices. Proceedings of the 25th ACM International Conference on Multimedia, 762-768.

Bueno, W. (1998). Jornalismo científico: Resgate de uma trajetória. Comunicação \& Sociedade, O(30), 209-220.

Bueno, W. C. (2010). Comunicação científica e divulgação científica: Aproximações e rupturas conceituais. Informação \& Informação, 15(1esp), 1-12.

Burkett, W. (1990). Jornalismo científico: Como escrever sobre ciência, medicina e alta tecnologia para os meios de comunicação. Forense Universitária.

Candotti, E. (2002). Ciência na educação popular. In L. Massarani, I. de Castro Moreira, \& F. Brito (Orgs.), Ciência e público: Caminhos da divulgação científica no Brasil (p. 15-24). Casa da Ciência - Centro Cultural de Ciência e Tecnologia da Universidade Federal do Rio de Janeiro.

Capozoli, U. (2002). A divulgação científica e o pulo do gato. In L. Massarani, I. de Castro Moreira, \& F. Brito (Orgs.), Ciência e público: Caminhos da divulgação científica no Brasil (p. 121-132). Casa da Ciência - Centro Cultural de Ciência e Tecnologia da Universidade Federal do Rio de Janeiro.

Christou, C., \& Parker, A. (1995). Visual realism and virtual reality: A psychological perspective. In K. Carr \& R. England (Orgs.), Simulated and Virtual RealitiesElements of perception (p. 53-85). Taylor\&Francis.

Comber, T. B., Pereira, L. G., \& da Silva, F. F. (2018). Narrativas em 360 Graus de Realidade Virtual no The New York Times e no El País: Jornalismo Imersivo e Distribuição Multiplataformas. Revista Temática, 14(2), 161-176.

Cordeiro, W. R., \& Costa, L. (2016). Jornalismo imersivo: Perspectivas para os novos formatos. Leituras do Jornalismo, 2(6), 99-116.

Dieb, D., \& Peschanski, J. A. (2017). Jornalismo Científico: Prática e Revisão de Literatura. 13. https://portalintercom.org.br/anais/nacional2017/resumos/R121217-1.pdf

Domínguez, E. (2017). Going Beyond the Classic News Narrative Convention: The Background to and Challenges of Immersion in Journalism. Frontiers in Digital Humanities, 4(10), 11.

Doyle, P., Gelman, M., \& Gill, S. (2016). Viewing the future? Virtual reality in journalism (p. 30). Knight Foundation. https://knightfoundation.org/wpcontent/uploads/2019/06/VR_report_web.pdf

Ebohon, G., \& Peschanski, J. A. (2017). Neuromatemática Representada: A imagem na difusão científica. 14. https://portalintercom.org.br/anais/nacional2017/resumos/R12-1220-1.pdf

Elmezeny, A., Edenhofer, N., \& Wimmer, J. (2018). Immersive Storytelling in 360-Degree Videos: An Analysis of Interplay Between Narrative and Technical Immersion. Journal For Virtual Worlds Research, 11(1), 13.

Filter, E., Eckes, A., Fiebelkorn, F., \& Büssing, A. G. (2020). Virtual Reality Nature Experiences Involving Wolves on YouTube: Presence, Emotions, and Attitudes in Immersive and Nonimmersive Settings. Sustainability, 12(9), 22. 
Foletto, J. P. F., \& Souza, M. D. (2019). Jornalismo imersivo ambiental: Estudo de vídeos em $360^{\circ}$ do National Geographic. Disciplinarum Scientia $\mid$ Ciências Humanas, 21(1), 233-246.

Fox, J., Arena, D., \& Bailenson, J. N. (2009). Virtual reality: A survival guide for the social scientist. Journal of Media Psychology: Theories, Methods, and Applications, 21(3), 95-113.

Gonçalves, M. (2012). Contribuição das mídias sociais digitais na divulgação científica. In L. V. R. Pinheiro \& E. da C. P. de Oliveira (Orgs.), Múltiplas facetas da

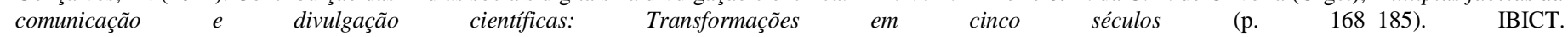
https://livroaberto.ibict.br/bitstream/1/711/1/M\%C3\%BAltiplas\%20facetas\%20da\%20comunica\%C3\%A7\%C3\%A3o\%20e\%20divulga\%C3\%A7\%C3\%A3o\%20ci ent $\%$ C3\%ADficas.pdf

Gonçalves, M. (2010). O Jornalismo Científico Brasileiro Diante da Nova Ordem $\quad$ Mundial Digital. 12. http://www.intercom.org.br/papers/nacionais/2010/resumos/R5-2670-1.pdf

Gorini, A., Capideville, C. S., De Leo, G., Mantovani, F., \& Riva, G. (2010). The Role of Immersion and Narrative in Mediated Presence: The Virtual Hospital Experience. Cyberpsychology, Behavior, and Social Networking, 14(3), 99-105.

Hardee, G. M. (2016). Immersive Journalism in VR: Four Theoretical Domains for Researching a Narrative Design Framework. In S. Lackey \& R. Shumaker (Orgs.), Virtual, Augmented and Mixed Reality (p. 679-690). Springer International Publishing.

Heeter, C. (1992). Being There: The Subjective Experience of Presence. Presence: Teleoperators and Virtual Environments, 1(2), $262-271$.

Jones, S. (2017). Disrupting the narrative: Immersive journalism in virtual reality. Journal of Media Practice, 18(2), 171-185.

Jun, H., Miller, M., Herrera, F., Reeves, B., \& Bailenson, J. (2020). Stimulus Sampling with 360-Videos: Examining Head Movements, Arousal, Presence, Simulator Sickness, and Preference on a Large Sample of Participants and Videos. IEEE Transactions on Affective Computing, 5(2), 112-125.

Kool, H. (2016). The Ethics of Immersive Journalism: A rhetorical analysis of news storytelling with virtual reality technology. Intersect: The Stanford Journal of Science, Technology, and Society, 9(3), Article 3. https://ojs.stanford.edu/ojs/index.php/intersect/article/view/871

Laws, A. L. S. (2020). Can Immersive Journalism Enhance Empathy? Digital Journalism, 8(2), 213-228.

Lin, Y.-C., Chang, Y.-J., Hu, H.-N., Cheng, H.-T., Huang, C.-W., \& Sun, M. (2017). Tell Me Where to Look: Investigating Ways for Assisting Focus in $360^{\circ}$ Video. Proceedings of the 2017 CHI Conference on Human Factors in Computing Systems, 2535-2545.

Longhi, R. R., \& Pereira, S. da C. (2016). Do panorama à realidade virtual: Como o ciberjornalismo está criando narrativas imersivas. XIII Congreso de la Asociación Latinoamericana de Investigadores de la Comunicación, Cidade do México, México. https://www.academia.edu/29156236/Do_panorama_\%C3\%A0_realidade_virtual_como_o_ciberjornalismo_est\%C3\%A1_criando_narrativas_imersivas

Mabrook, R., \& Singer, J. B. (2019). Virtual Reality, $360^{\circ}$ Video, and Journalism Studies: Conceptual Approaches to Immersive Technologies. Journalism Studies, 20(14), 2096-2112.

Makransky, G., Terkildsen, T. S., \& Mayer, R. E. (2019). Adding immersive virtual reality to a science lab simulation causes more presence but less learning. Learning and Instruction, 60, 225-236.

Maschio, T. (2017). Storyliving: An Ethnographic Study of How Audiences Experience VR and What That Means for Journalists (p. 27). Google News Lab. https://newslab.withgoogle.com/assets/docs/storyliving-a-study-of-vr-in-journalism.pdf

Mikropoulos, T. A., \& Natsis, A. (2011). Educational virtual environments: A ten-year review of empirical research (1999-2009). Computers \& Education, 56(3), 769-780.

Moreira, I. de Castro, \& Massarani, L. (2002). Aspectos históricos da divulgação científica no Brasil. In L. Massarani, I. de Castro Moreira, \& F. Brito (Orgs.), Ciência e público: Caminhos da divulgação científica no Brasil (p. 43-64). Casa da Ciência - Centro Cultural de Ciência e Tecnologia da Universidade Federal do Rio de Janeiro.

Nikolic, D. (2007). Evaluating relative impact of virtual reality components detail and realism on spatial comprehension and presence [Doutorado, Pennsylvania State University]. http://www.pennstatecic.org/uploads/5/1/2/1/51219339/tr_053_zikic_2007_vr_in_arch.pdf

Owen, T., Pitt, F., Aronson-Rath, R., \& Milward, J. (2015, novembro). Virtual Reality Journalism. Columbia Journalism Review. https://www.cjr.org/tow_center_reports/virtual_reality_journalism.php/

Pan, Z., Cheok, A. D., Yang, H., Zhu, J., \& Shi, J. (2006). Virtual reality and mixed reality for virtual learning environments. Computers \& Graphics, 30(1), $20-28$.

Peña, N. de la, Weil, P., Llobera, J., Spanlang, B., Friedman, D., Sanchez-Vives, M. V., \& Slater, M. (2010). Immersive Journalism: Immersive Virtual Reality for the First-Person Experience of News. Presence, 19(4), 291-301.

Pérez Seijo, S. (2017). Immersive Journalism: From Audience to First-Person Experience of News. In F. C. Freire, X. Rúas Araújo, V. A. Martínez Fernández, \& X. L. García (Orgs.), Media and Metamedia Management (p. 113-119). Springer International Publishing.

Pinheiro, C. M. P., Barth, M., \& Fetzner, M. N. (2014). Newsgames e o papel do jornalismo na cultura da convergência. Estudos em Jornalismo e Mídia, 11(2), 510521. 
Porto, C. de M. (2009). A internet e a cultura científica no Brasil: Difusão da ciência. In C. de M. Porto (Org.), Difusão e cultura científica: Alguns recortes (p. 149165). EDUFBA. http://books.scielo.org/id/68

Reis, A. B., \& Coelho, A. F. V. C. C. (2018). Virtual Reality and Journalism. Digital Journalism, 6(8), 1090-1100.

Rupp, M. A., Odette, K. L., Kozachuk, J., Michaelis, J. R., Smither, J. A., \& McConnell, D. S. (2019). Investigating learning outcomes and subjective experiences in 360-degree videos. Computers \& Education, 128, 256-268.

Ryan, M.-L. (1999). Immersion vs. Interactivity: Virtual Reality and Literary Theory. SubStance, 28(2), 110-137.

Shin, D., \& Biocca, F. (2017). Exploring immersive experience in journalism. New Media \& Society, 20(8), 2800-2823.

Slater, M. (2009). Place illusion and plausibility can lead to realistic behaviour in immersive virtual environments. Philosophical Transactions of the Royal Society B: Biological Sciences, 364(1535), 3549-3557.

Slater, M., Khanna, P., Mortensen, J., \& Yu, I. (2009). Visual realism enhances realistic response in an immersive virtual environment. IEEE Computer Graphics and Applications, 29(3), 76-84.

Slater, M., \& Wilbur, S. (1997). A Framework for Immersive Virtual Environments (FIVE): Speculations on the Role of Presence in Virtual Environments. Presence: Teleoperators and Virtual Environments, 6(6), 603-616.

Steuer, J. (1992). Defining Virtual Reality: Dimensions Determining Telepresence. Journal of Communication, 42(4), $73-93$.

Sundar, S. S., Kang, J., \& Oprean, D. (2017). Being There in the Midst of the Story: How Immersive Journalism Affects Our Perceptions and Cognitions. Cyberpsychology, Behavior and Social Networking, 20(11), 672-682.

Teixeira, M. (2002). Pressupostos do jornalismo de ciência no Brasil. In L. Massarani, I. de Castro Moreira, \& F. Brito (Orgs.), Ciência e público: Caminhos da divulgação científica no Brasil (p. 133-141). Casa da Ciência - Centro Cultural de Ciência e Tecnologia da Universidade Federal do Rio de Janeiro.

Torres, C. C. (2017). O discurso mêmico na construção de novas formas de linguagem sobre divulgação científica através de mídias sociais [Mestrado, UNICAMP]. http://repositorio.unicamp.br/jspui/handle/REPOSIP/330449

Valerio, P. M. (2012). Comunicação científica e divulgação: O público na perspectiva da internet. In L. V. R. Pinheiro \& E. da C. P. de Oliveira (Orgs.), Múltiplas facetas da comunicação e divulgação científicas: Transformações em cinco séculos (p. 150-167). IBICT. https://livroaberto.ibict.br/bitstream/1/711/1/M\%C3\%BAltiplas\%20facetas\%20da\%20comunica\%C3\%A7\%C3\%A3o\%20e\%20divulga\%C3\%A7\%C3\%A3o\%20ci ent $\%$ C3\%ADficas.pdf

van Gisbergen, M., Kovacs, M., Campos, F., van der Heeft, M., \& Vugts, V. (2019). What We Don't Know. The Effect of Realism in Virtual Reality on Experience and Behaviour. In M. C. Tom Dieck \& T. Jung (Orgs.), Augmented Reality and Virtual Reality: The Power of AR and VR for Business (p. 45-57). Springer International Publishing.

Watson, Z. (2017). VR for News: The New Reality? Reuters Institute for the Study of Journalism. https://www.digitalnewsreport.org/publications/2017/vr-news-newreality/

Witmer, B. G., \& Singer, M. J. (1998). Measuring Presence in Virtual Environments: A Presence Questionnaire. Presence: Teleoperators and Virtual Environments, $7(3), 225-240$.

Wu, C., Tan, Z., Wang, Z., \& Yang, S. (2017). A Dataset for Exploring User Behaviors in VR Spherical Video Streaming. Proceedings of the 8th ACM on Multimedia Systems Conference, 193-198.

Yin, R. K. (2001). Estudo de caso: Planejamento e métodos (2ºd). Bookman. 